\title{
A CONTROVÉRSIA DE UM DEBATE PÚBLICO: AS SALAS DE USO DE DROGAS NA FRANÇA
}

\section{ARTIGO DE REVISÃO}

MENDONÇA, Natália Heringer [1], BENTO, Nárgila Mara da Silva [2], ALMEIDA, Dulce Maria Filgueira de [3]

MENDONÇA, Natália Heringer. BENTO, Nárgila Mara da Silva. ALMEIDA, Dulce Maria Filgueira de. A controvérsia de um debate público: as salas de uso de drogas na França. Revista Científica Multidisciplinar Núcleo do Conhecimento. Ano. 06, Ed. 11, Vol. 01, pp. 61-79. Novembro 2021. ISSN: 2448-0959, Link de acesso: https://www.nucleodoconhecimento.com.br/ciencias-sociais/drogas-na-franca, DOI: 10.32749/nucleodoconhecimento.com.br/ciencias-sociais/drogas-na-franca

\section{RESUMO}

O presente estudo originou-se do esforço em compreender o contexto social da implantação de Salas de Consumo a Risco Reduzido para usuários de drogas injetáveis tomando por base o caso da França, que autorizou a abertura destes estabelecimentos em 2016. Tendo em conta que o uso de psicoativos foi longamente combatido por meio de uma política proibicionista que vigorou a partir de 1970 no país, surge a seguinte questão norteadora: quais foram os aspectos sociais que levaram à adoção de um outro modelo, até então moralmente muito contestado por sua sociedade, que aceita o uso moderado e em ambientes apropriados daquelas substâncias? $\mathrm{O}$ artigo tem por objetivo analisar a constituição discursiva interposta acerca das Salas de Consumo no debate público francês. Realizamos uma pesquisa de natureza teórica empregando uma metodologia qualitativa, a qual tratou-se de uma revisão bibliográfica não-exaustiva, feita em 2019, incluindo artigos científicos e teses. A principal base de consulta foi constituída pela Biblioteca Nacional e Universitária de Estrasburgo. Os resultados apontam que, segundo o material analisado, a genealogia acerca do uso de substâncias psicoativas está 
relacionada à estigmatização dos usuários. O aspecto social que conduziu a passagem do proibicionismo à adoção do modelo de moderação no uso de psicoativos ocorreu através de um campo de controvérsias que inseriu, paulatinamente, o tema da redução de danos no debate público francês. Além disso, até o momento da pesquisa, havia uma escassa produção científica sobre a temática, a despeito de sua importância para o debate público. Conclui-se que a superação das controvérsias acerca do assunto pode contribuir para a (des)estigmatização de usuários de substâncias psicoativas, redefinindo seu papel social e status nos processos de interação em sociedade.

Palavras-chave: Debate público, Substâncias Psicoativas, Salas de Consumo a Risco Reduzido, França.

\section{INTRODUÇÃO}

$\mathrm{Na}$ constituição das sociedades humanas o uso de substâncias psicoativas sempre foi uma constante. Utilizadas em processos rituais, seja em cerimoniais religiosos ou em circunstâncias festivas hedonísticas, essas substâncias sempre foram parte das culturas humanas (ESCOHOTADO, 2008). Por volta da década de 1980, a epidemia decorrente da Síndrome da Imunodeficiência Adquirida (AIDS), bem como o aumento de infecções decorrente da Hepatite $C$ (sexualmente transmissível) provocaram discussões acerca do consumo de substâncias psicoativas, notadamente àquelas de natureza injetável. Nesse período, uma reformulação da saúde pública era discutida por diversos atores da esfera internacional, instituindose, assim, um debate público. Uma reorganização das políticas públicas de saúde centrada no modo de vida das pessoas diretamente afetadas por suas medidas era reivindicada, assim como a adequação dessas medidas à realidade das populações (JAUFFRET-ROUSTIDE; CAILBAULT, 2018). Nessa ótica, o uso moderado das substâncias em estabelecimento apropriado aparecia como uma alternativa plausível considerando o contexto social, para além da abstinência dos usuários. 
Garrau (2018), na obra Politiques de la vulnérabilité, explica que a concepção de Platão sobre o ser humano racional consiste num indivíduo ideal que controla totalmente os seus desejos, o que vem assentar a lógica da abstinência. Em contraposição à noção platônica, Aristóteles (1992) em Éthique à Nicomaque contribui ao elaborar a ideia de temperança, que fundamentaria a lógica da moderação. Finalmente, mesmo sem mencionar explicitamente essas lógicas, no artigo Le contrecorps de la toxicomanie, Le Breton (2012a) dialoga com a noção de que recorrer às drogas é moralmente viável e a inclui no conjunto de condutas ordálicas, explanadas em Sociologie du risque (LE BRETON, 2012b).

Segundo o Observatório Europeu da Droga e da Toxicodependência (OEDT, 2017), a primeira sala de injeção supervisionada foi inaugurada na Suíça em 1986. Hoje, o país oferece 12 dessas estruturas. A Alemanha autorizou o seu funcionamento em 2000 e, atualmente, conta com 24 estabelecimentos. A Espanha possui 13 e a Holanda disponibiliza 31 espaços do mesmo tipo. Há ainda duas na Noruega, uma em Luxemburgo e quatro na Dinamarca. Outras existem ainda no Canadá e na Austrália. Na França, mesmo fora do quadro legal, uma primeira Sala de Consumo foi aberta em 1994 pelo grupo Auto-support des usagers de drogue[4] (ASUD) em Montpellier. Entretanto, o estabelecimento foi fechado depois da overdose de uma jovem em 1995. Após esse episódio, as Salas de Consumo só receberiam autorização legal de funcionamento em 2016.

No que diz respeito ao contexto francês, Jauffret-Roustide e Cailbault (2018) mostram os contornos dramáticos que o debate sobre o tema ganhou na cobertura da imprensa. Os argumentos mais evocados pelas mídias a favor das Salas de Consumo argumentavam que elas favoreciam à diminuição das taxas de overdose e da contaminação por doenças transmissíveis. Entretanto, a profusão de argumentos era bem menor em relação àqueles que enfatizavam a tranquilidade social resultante da diminuição do consumo em espaços públicos e a diminuição da exposição à humilhação moral e social dos usuários que sofrem com o sentimento de vergonha e medo.

RC: 100364

Disponível em: https://www.nucleodoconhecimento.com.br/ciencias-sociais/drogasna-franca 
Nos anos 2000, mesmo que a maioria do pessoal da saúde tivesse aderido ao discurso da redução de danos à saúde, argumentos ainda eram veiculados pela imprensa segundo os quais as Salas de Consumo seriam a perpetuação do mal que uma pessoa pode fazer a si mesma. No contexto micro, a controvérsia é intensa, principalmente em Paris, no Quartier Gare, onde a Sala de Consumo parisiense foi instalada. Neste bairro, muitos se opõem às salas por temerem que a marginalização dos moradores seja acentuada e eles sejam colocados em situação de perigo. Por sua vez, acredita-se que a Sala de Consumo de Strasbourg não sofreu com a oposição dos moradores porque sua implantação foi prevista para ser feita nas instalações do hospital universitário.

Posto isso, considerando que o uso de psicoativos foi combatido pela França por meio de um modelo proibicionista a partir de 1970, surge a questão norteadora: quais foram os aspectos sociais que levaram à adoção de um outro modelo, até então moralmente muito contestado por sua sociedade, o qual aceita o uso moderado e em ambientes apropriados daquelas substâncias? Assim, o presente artigo[5] tem por objetivo analisar, com base em uma pesquisa bibliográfica, a constituição discursiva interposta entre o proibicionismo e o paradigma da saúde acerca da institucionalização de estabelecimentos, denominados de Salas de Consumo a Risco Reduzido, destinados a usuários de substâncias psicoativas injetáveis na França.

\section{AS SALAS DE CONSUMO, ABSTINÊNCIA E MODERAÇÃO: ASPCETOS DE UM DEBATE PÚBLICO MORAL}

A controvérsia sobre a implantação das Salas de Consumo evidencia o aspecto moral do processo que levou a sua autorização, pois mostra a reformulação do discurso sobre aquilo que se compreende como conduta desejável e aceitável em nossa sociedade. Ela se inscreve na genealogia da transição do proibicionismo para a redução de danos. Essa passagem mostra como o sujeito contestador dos anos 1970 se tornou o junky e o marginal dos anos 1980 e o adicto dos anos 1990. Por 
esse caminho que concebe e designa o usuário de modos diferentes, também passam diferentes construções do sujeito.

Em Le sujet et le pouvoir, Foucault (1982) discerne acerca das formas de constituição do sujeito, trazendo um preciso aporte teórico para compreendermos como a lógica que se instalou com o paradigma da redução de riscos à saúde institui uma nova forma de apreensão do usuário de drogas. Associa-se à essa ideia o seu livro Surveiller et punir. Naissance de la prison (FOUCAULT, 1975), em que vemos como operam as lógicas que assujeitam os chamados corpos dóceis. A esse respeito, Foucault (1982) esclarece que o termo "sujeito" possui pelo menos duas acepções: na primeira, o indivíduo é assujeitado a alguém ou a algo; na segunda, ele é o autor de um sentido que é implicado em uma ação. Todavia, nos dois casos, o autor sustenta que existe um poder agindo sobre o sujeito. Essa assertiva se baseia na teoria da ação racional, segundo a qual toda ação é precedida da atribuição de intenção que Ihe dá sentido. Essa característica é concebida, desde a filosofia grega, como a principal qualidade que distingue os seres humanos dos animais. Ao dar uma intenção a cada ação e agindo de modo a atingi-la, o indivíduo se consagra como sujeito de suas ações e, consequentemente, como sujeito de si. Isso porque, ao refletir sobre uma decisão, ele coloca em prática sua capacidade de se autodeterminar.

Para realizar essa atribuição de sentido, o sujeito usa suas referências aprendidas no decorrer das interações sociais e as significações que ele thes dá. Portanto, Foucault (1982) ressalta, mesmo no agir individualmente motivado, o sujeito é submetido a uma força exterior. Nesse sentido, o autor sustenta que saberes específicos influenciam as maneiras igualmente específicas pelas quais uma pessoa atribui sentido tanto às suas próprias ações quanto a si mesmo. Por exemplo, a lógica da proibição-abstinência propagada nos anos 1970 veiculou crenças a respeito do consumo de drogas que persistiram por muito tempo e, ainda hoje, vemos algumas pessoas se referindo aos usuários de drogas como toxicômanos. Efeitos da psiquiatria da época, o ideal de abstinência e a teoria da escalada classificaram, isolaram, medicaram, puniram e institucionalizaram aqueles que 
estavam fora da adequação social. Por isso, trata-se de um saber que torna possível o exercício de um poder específico, nas palavras de Foucault (1982), de um podersaber.

Em matéria de uso de drogas, a política da proibição definiu a pessoa que faz esse consumo como problema; o saber psiquiátrico da década de 1970 o legitimou ao estabelecer o que é a toxicomania e seus estágios. Nesse contexto, uma disciplina (FOUCAULT, 1975) específica vem regularizar os usos que os indivíduos fazem das diferentes substâncias. De acordo com esse rito, os indivíduos se imputam uma autovigilância quanto às quantidades, os tipos de drogas, a frequência, as formas de consumo e, além disso, julgam se eles se encaixam como pessoas supostamente normais ou se são leve, moderada ou profundamente viciadas.

No entanto, destacamos que, na ação racional, o processo de atribuição de sentidos é constante e se repete a cada ação. Sendo assim, se por um lado os sujeitos são condicionados pela internalização das normas, por outro, eles têm a capacidade de ressignificar suas experiências (JOAS, 2001). Dessa forma, eles também reinterpretam constantemente o modo como concebem a eles mesmos.

Trazendo esse raciocínio para o nosso tema, a maneira pela qual os usuários se apropriam de suas experiências com as drogas expressa formas muito particulares de uso, tão singulares quanto podem ser as ressignificações dessas substâncias e de si. Por exemplo, muitos procuram não recorrer aos meios institucionais, fazendo eles próprios os ciclos de substituição com medicamentos, como codeína e metadona (KOKOREFF et al., 2018). Outros notam que seu vício está ligado à injeção e passam a introduzir outros líquidos como a água (DOS SANTOS, 2016). Portanto, se a disciplina no uso de drogas subjetiva os indivíduos, alguns se subjetivado como normais e outros como toxicômanos, também há indícios de que essa significação será reformulada pelo sujeito.

Nesse contexto, percebemos que, na passagem do proibicionismo para a redução de danos, o predomínio da lógica da abstinência deu lugar àquela da moderação. No 
proibicionismo, a adesão ao ideal de abstinência em relação a algumas drogas produziu uma espécie de corpo dócil (FOUCAULT, 1975) e, até recentemente, separava os que aderiam a esse ideal dos que dele desviavam, encarcerando os últimos em prisões ou em instituição psiquiátrica. Contudo, na redução de danos, a adesão à ideia de moderação vai "docilizar" os corpos de outro modo: pelo acesso controlado ao prazer e ao risco. Como o sujeito continua agente de sua escolha, o encarceramento se dá no plano das ideias, pois o sujeito fica preso na própria responsabilidade de controle do uso da droga.

A fim de esclarecer as lógicas da abstinência e da moderação, recorremos à discussão iniciada por Platão e Aristóteles sobre o agir humano. A moral platônica parte da separação entre mundo sensível e mundo das ideias, o primeiro relacionado ao corpo e o segundo, à mente. Para ele, o sensível é a expressão das sensações, dos desejos do corpo, que nos enganam facilmente. Quando motivado por eles, o sujeito ficaria mais exposto à incerteza. Assim, para neutralizá-los, é necessário que o indivíduo exista pela razão, pois ela permite dominar o desejo. Logo, conforme essa moral, a vida deve ser asséptica, autossuficiente e isenta de paixões corporais (GARRAU, 2018). Tal afirmação de autonomia extrema e negação da sensibilidade são a base do ideal de abstinência.

Aristóteles (1992) também pensa que o domínio da incerteza passa pela restrição dos desejos. No entanto, ele não propõe a negação do mundo sensível, mas o acesso a ele por meio da temperança. Esta é, segundo o filósofo, uma virtude moral, ou seja, ela é uma disposição que os sujeitos constroem a partir do aprendizado e de boas práticas. Ela consiste no meio termo entre o excesso e a falta de algum desejo, no caso, o desejo dos prazeres do corpo além ou aquém das necessidades naturais (ARISTÓTELES, 1992). A abordagem aristotélica interessa ao nosso estudo, pois não se trata da procura pelo prazer, mas a busca pelo seu excesso, o que caracteriza a irracionalidade. Assim, usando de temperança, a ação que visa atingir o prazer pode se tornar racional.

RC: 100364

Disponível em: https://www.nucleodoconhecimento.com.br/ciencias-sociais/drogasna-franca 
Percebemos, desse modo, uma semelhança de sentido entre o conceito de temperança e o de moderação presente na política de redução de danos quanto ao uso de drogas. Nesse caso, as boas práticas de consumo criam a disposição para o agir racional. Isto é, o indivíduo emprega sua racionalidade, uma vez que recorre à substância psicoativa, escolhendo fazê-la sem excesso, seja do produto ou do risco à saúde. Nesse contexto, a moderação manteria a dignidade da pessoa pela crença no uso controlado como uma maneira de coexistir com o uso da droga. Esse controle diz respeito à quantidade, frequência e modos que comportem menos riscos de uso, representando a tentativa de racionalizar o consumo pela diminuição da exposição do indivíduo à incerteza dos possíveis danos.

Mais recentemente, Le Breton (2012a) aborda o uso de drogas na perspectiva da relação entre desejo e dor. Ele se soma às abordagens que foram importantes para a contestação da visão problemática relativa ao usuário de entorpecentes e que tiram o foco da abstinência. Trata-se de conceber os usuários fora de um perfil suicidário, mas como pessoas que procuram tornar suas vidas possíveis. $O$ autor afirma que a dependência se origina na ação empreendida pelo sujeito visando dar fim a uma dor involuntária. Esta é, temporariamente, substituída por uma dor voluntária, à saber, o uso da droga. O autor inscreve esse consumo entre as condutas ordálicas. Nesse tipo de comportamento, a pessoa procura dar um valor a sua própria vida por meio de experiências perigosas às quais ela se expõe (LE BRETON, 2012b).

Inicialmente, a dor voluntária, controlável e que substitui aquela involuntária, permite dar um sentido a si mesmo, estar presente e conter seu vazio existencial. Ela também tende a aliviar a existência em um mundo individualista confuso, sufocante, no qual os sofrimentos são encobertos e as relações são incertas. Durante a dependência, entretanto, o usuário se torna fortemente ligado a esse alívio, do qual a procura temporária se transforma em permanente (LE BRETON, 2012a).

Por essa razão, o usuário vive em um constante vai e volta entre sensações, o que possibilita não estar totalmente imerso no sofrimento nem na ideia de dar fim à 
existência. Trata-se de um tempo cíclico, no qual a pessoa alterna a intensidade das sensações provocadas pela droga e a falta dela (LE BRETON, 2012a). É um tempo próprio criado pela pessoa e pela sua gestão da dor involuntária. Consequentemente, para o autor, o usuário procura reproduzir aquele alívio para que possa se manter no pertencimento ao mundo à própria maneira e não porque aspire à morte. Esta forma de compreender o usuário enquanto um sujeito que busca dar sentido à vida dialoga com os argumentos que vieram a sustentar a implantação das Salas de Consumo na França.

De fato, o debate público se desenvolveu em escala local e foi graças à iniciativa dos defensores da redução de danos que essa discussão ganhou maior visibilidade, principalmente a partir de 2009. Os ativistas realizaram eventos para apresentar a questão aos espaços públicos e pediram aos políticos locais para que procurassem conhecer as salas similares em outros países. Depois dessa mobilização, o Institut National de la Santé et de la Recherche Médicale[6] (INSERM) afirmou, em 2010, que as Salas de Consumo deveriam ser instalados em caráter experimental e cientificamente avaliados (JAUFFRET-ROUSTIDE; CAILBAULT, 2018).

$\mathrm{Na}$ perspectiva da sociologia pragmática, a publicização da demanda para um espaço de consumo de drogas, acentuada pelos ativistas de 2009, provocou uma "subida em generalidade" (BOLTANSKI; THÉVENOT, 1991) do problema da condição penível dos usuários. O termo em destaque indica que um problema tido como singular tende a ser compreendido como coletivo por meio de um processo no qual o debate público entre atores que compõem o campo das controvérsias traz um problema de uma microesfera para a macroesfera.

Assim, a publicização do debate incentivou outros a se sensibilizarem e suscitou a empatia do público pelos usuários (JAUFFRET-ROUSTIDE; CAILBAULT, 2018). Como essa exposição levou os cidadãos, os usuários e os políticos locais a integrar o campo do debate, a diversidade de argumentos atenuou a força do discurso moral da abstinência e daqueles que o sustentavam. Ou seja, a pluralidade de pensamentos engendrou uma crítica do que estava em vigor até aquele momento a

RC: 100364

Disponível em: https://www.nucleodoconhecimento.com.br/ciencias-sociais/drogasna-franca 
respeito de como lidar como o uso de drogas e permitiu um novo compromisso: experimentar as salas de consumo de risco reduzido. Portanto, a ação de pequenos grupos e a publicidade do debate, acrescidos da manifestação do INSERM, levariam à futura autorização das Salas de Consumo a título experimental.

Interessante observar que a autorização da implantação das Salas de Consumo condicionada à experimentação tornou possível a conjugação do uso de drogas com o seu o concomitante controle, levantamento de dados e análises. Ela reforça ainda a posição de destaque de alguns atores sociais no campo da saúde, notadamente aqueles que, ao atualizarem seus discursos, mantêm sua importância no campo durante os anos de experimentação. Foi o caso do INSERM, que depois de ter emitido nota favorável e condicionado a implantação das salas ao exame por especialistas, tornou-se o órgão responsável pela sua avaliação.

Atualmente, as Salas de Consumo são analisadas por dois programas de pesquisa (MILDECA, 2016). O Cosinus, avaliação socioepidemiológica conduzida pelo INSERM que compara a melhoria das condições socio-sanitárias e as práticas de redução de danos dos usuários de uma Sala de Consumo em contraste com usuários que não as frequentam. Uma segunda avaliação estuda a aceitabilidade social das Salas de Consumo e seu impacto na tranquilidade social. Ela é realizada pelo Centre de recherche médecine, sciences, santé, santé mentale, société[7] (CERMES3), laboratório multidisciplinar que emprega a observação etnográfica dos espaços públicos e entrevistas de usuários, de atores da redução de danos, associações e moradores.

Entretanto, cabe ressaltar que o uso de entorpecentes continua sendo um delito na França. Os usuários de psicoativos sabem que ainda podem ser punidos -quando fazem uso destas substâncias fora de um ambiente como o das Salas de Consumo - com uma reclusão de até um ano e uma multa de 3.750 euros, ou com pena alternativa a ser definida por um juiz. Esta pode se traduzir por trabalho não remunerado, estágio de sensibilização aos perigos das drogas e injunção 
terapêutica. Ou seja, do ponto de vista legal, a proibição foi flexibilizada, mas não extinta.

\section{METODOLOGIA}

Como mencionado, com o objetivo de analisar, com base em uma pesquisa bibliográfica, a constituição discursiva interposta acerca das Salas de Consumo a Risco Reduzido no debate público francês, realizamos uma pesquisa de natureza teórica, utilizando uma metodologia qualitativa, tendo como modelo de estudo a pesquisa bibliográfica. Tratou-se de uma revisão bibliográfica não-exaustiva, incluindo os seguintes tipos de documentos: artigos científicos e teses. A base de consulta foi constituída pela Biblioteca Nacional e Universitária de Estrasburgo e, de modo complementar, utilizamos o Google, tanto acadêmico quanto convencional. Nas buscas, foram inseridos como descritores as palavras-chave: "Sala de consumo a risco reduzido"; "redução de danos"; "controle de uso de drogas"; "políticas antidroga". E como operadores booleanos usamos "AND" e "OR". Não definimos marco temporal.

Foram encontrados quatro artigos e três teses referentes ao período de 2000 até o ano de 2018, como se vê no Quadro a seguir.

QUADRO 1 - Documentos Identificados na Primeira Busca

\begin{tabular}{|c|c|c|c|}
\hline \multicolumn{2}{|c|}{ Título } & Tipo & Ano \\
\hline 1 & $\begin{array}{l}\text { Entre politiques du vivant et politiques de la vie: pour une } \\
\text { anthropologie de la santé. }\end{array}$ & Artigo & 2000 \\
\hline 2 & Le contrecorps de la toxicomanie. & Artigo & 2012 \\
\hline 3 & $\begin{array}{l}\text { Usages de traitements de substitution aux opiacés: étude } \\
\text { comparative: France, Suisse et Québec. }\end{array}$ & Tese & 2016 \\
\hline 4 & Les salles de consommation à moindre risque. & Artigo & 2016 \\
\hline 5 & $\begin{array}{l}\text { L'addiction comme pathologie de la volonté: repenser } \\
\text { l'impuissance de la volonté à la lumière des sciences cognitives. }\end{array}$ & Tese & 2017 \\
\hline
\end{tabular}

RC: 100364

Disponível em: https://www.nucleodoconhecimento.com.br/ciencias-sociais/drogasna-franca 


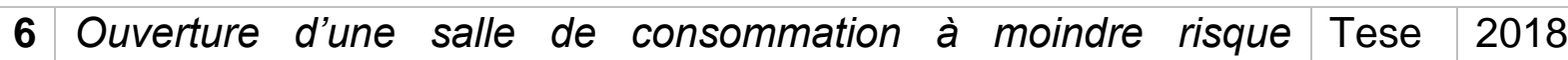
(SCMR): attentes des usagers de drogues. 2018.

7 Drug consumptionrooms: comparing times, spaces and actors in Artigo 2018 issues of social acceptability in French public debate.

Fonte: própria (2021).

Considerando o total de materiais obtidos, consoante a leitura, percebemos a necessidade de realizar uma nova busca com os temas, "proibição de drogas", "proibicionismo", "moderação", "temperança" e "controvérsia", utilizando-se os mesmos operadores booleanos. Não foram obtidos artigos científicos e teses com estes descritores, exceto quatro livros, que serão utilizados como suporte na análise.

Consecutivamente à primeira e à segunda busca mencionadas, procedemos à leitura, categorização, análise e discussão. A análise dos documentos obtidos se deu consoante a análise de conteúdo (BARDIN, 2009). A partir da leitura inicial dos documentos, elegemos a temática "genealogia" para análise, posto que era o tema recorrente nos estudos apresentados. Essa temática foi, portanto, considerada conteúdo exposto no debate público acerca da constituição discursiva interposta entre o proibicionismo e o paradigma da redução de danos à saúde acerca da institucionalização de estabelecimentos denominados de Salas de Consumo a Risco Reduzido na França.

\section{DA GENEALOGIA À ESTIGMATIZAÇÃO}

Como percebemos a partir do Quadro acima, a produção científica na França sobre a temática ainda é incipiente. Foram identificadas apenas três teses e quatro artigos científicos. Analisando-os separadamente, podemos perceber que as teses e artigos estão concentrados no período de 2000 a 2018, indicando que há uma relação entre o marco temporal da produção científica e a abertura da primeira Sala de Consumo a Risco Reduzido na França, o que ocorreu extraoficialmente em 1994 e oficialmente em 2016, como visto anteriormente. Outro fator a ser destacado é a

RC: 100364

Disponível em: https://www.nucleodoconhecimento.com.br/ciencias-sociais/drogasna-franca 
institucionalização do debate público internacional sobre a temática, que em alguns países europeus, como a Alemanha, ganha ainda mais fôlego no início dos anos 2000.

A análise empreendida considerou, com base nos documentos obtidos (artigos científicos e teses), o conceito - conteúdo - "genealogia". Para tanto, enveredamos na mediação desse conceito e na apropriação da noção de "estigma" (GOFFMAN, 2004) para a análise.

Destacamos a obra coletiva dirigida por Michel Kokoreff, Anne Coppel e Michel Peraldi (2018) que, igualmente, foi tomada como referência para a discussão. A obra aborda a questão da genealogia do nosso tema. Nela, os autores se referem ao período originário na França do uso de substâncias psicoativas como um período de catástrofe invisível. Um quadro cronológico de uma história invisível e não linear é proposto na introdução separando um período de descoberta (1964-1973), um de oscilação (1973-1987) e um outro de refluxo (1988-1996). Nesse quadro, os anos 1960 marcam o tempo em que a heroína era essencialmente utilizada por artistas, alguns escritores e principalmente os diplomados, enquanto a elite financeira usava preferencialmente a cocaína. No decorrer desse período, uma grande quantidade de heroína, conhecida como marseillaise, era exportada de Marseille para os Estados Unidos pela chamada french connexion (KOKOREFF et al., 2018).

Passamos então às abordagens acerca da genealogia presente nos artigos científicos e teses. Fassin (2000), em seu artigo, traz a perspectiva de sanitarização do social para entender como se dá o processo de construção de um problema de saúde pública. O primeiro artigo de Jaufret-Roustide (2016) examina as Salas de Consumo como meio de reduzir a degradação socialmente construída dos usuários. A tese de Dos Santos (2016) analisa como o ideal de abstinência presente no proibicionismo foi relativizado e conduziu a um processo de normalização das condutas aditivas. A tese de Trouessin (2017) discorre sobre a transição na maneira de apreender a pessoa - de toxicômano a usuário - e o respectivo uso de drogas de toxicomania a adição a psicoativos. Na terceira tese obtida, Valentin (2018) 
observa o início do funcionamento da sala de Strasbourg e explica que nela se oferece aos usuários material asséptico para uso de droga injetável, como seringas e agulhas descartáveis e lenços próprios para evitar septicemias. $\mathrm{O}$ artigo de Jaufret-Roustide e Cailbault (2018) emprega a sociologia das controvérsias para analisar, através da observação do debate público na imprensa escrita local e nacional nas mídias francesas, como se deu a implantação das Salas de Consumo a Risco Reduzido.

Jauffret-Roustide e Cailbault (2018) salientam que a forte polarização entre a abertura intelectual da saúde pública e o apego à ideia de abstinência deram um ar muito emocional às discussões sobre o problema das drogas. Isso fez com que posições complementares fossem consideradas como opostas. O fato de a imprensa ter tratado as controvérsias como polarização marcou a discussão a respeito das Salas de Consumo de forma muito mais dramática do que as pesquisadoras observaram em campo.

Levando em conta os usuários de drogas injetáveis, se no plano social foram marginalizados e excluídos do acesso a seus direitos, no plano sanitário acabaram por se distanciar do sistema de cuidados com a saúde (JAUFFRET-ROUSTIDE, 2016). Kokoreff et al. (2018) abordam o contexto social e histórico em que o uso de substâncias psicoativas se tornou um problema social na França, desdobrando-se em uma política proibicionista. As consequências disso vão além das overdoses ou da contaminação por HIV e Hepatite C, englobando igualmente as septicemias ou outros problemas de saúde que não encontravam tratamento. Da grávida ao cardíaco, vários usuários não buscavam os serviços de saúde devido ao medo do controle e da estigmatização. Diante da dimensão desses problemas, é difícil calcular o número de mortes de fato provocadas pelo uso de drogas injetáveis.

De acordo com Goffman (2004, p. 22), "no estudo sociológico das pessoas estigmatizadas, o interesse está geralmente voltado para o tipo de vida coletiva, quando esta existe, que levam aqueles que pertencem a uma categoria particular". $\mathrm{Na}$ acepção do autor, os sinais corporificados, isto é, materializados nos corpos das 
pessoas, podem engendrar mecanismos de prestígio ou de estigmatização, contudo, ambos são marcadores da identidade social das pessoas, no nosso caso, dos frequentadores das Salas de Consumo a Risco Reduzido.

A heroína começou a fazer parte, na França, dos ciclos de relações sociais ligadas à afluência dos hippies e dos freaks ${ }^{[8]}$ que atravessavam o território francês. Nos anos 1970, esse produto teve uma difusão sem precedentes com a multiplicação dos fornecedores de vários países como a Turquia, o Líbano, o Paquistão, a Tailândia e o Irã (KOKOREFF et al., 2018). A intensificação do tráfico acarretou cenas de venda ao ar livre dos anos 1980 e o significativo número de prisões de jovens das cités[9], que eram os mais perseguidos pela polícia. Isso colocou em marcha uma máquina penal que se estenderia pelo decênio seguinte. Os anos 1990 foram, então, marcados por: uma luta contra os traficantes de rua, um refluxo dos usuários que envelheciam e se encontravam em grande penúria e, finalmente, pelo Islã se apresentando como um ponto de apoio para sair da dependência das drogas. Esse também foi o momento em que o discurso da redução de danos emergiu.

Especificamente quanto aos anos 1960, o senso comum não associava as drogas à juventude, pois o consumo não era uma temática conhecida, mesmo entre educadores e professores (KOKOREFF et al., 2018). A partir de 1964, os jovens se tornam atores sociais politicamente mais engajados e, em 1968, eles se juntaram aos trabalhadores num movimento social que ficou conhecido como Maio de $68 . \mathrm{Na}$ Paris desse período, a juventude descobria outras formas de vida além daquelas ligadas ao binarismo operariado-burguesia. Era um contexto de experimentação, entre elas, a das drogas: canabis, LSD, anfetaminas, medicamentos desviados, heroína, metanfetamina e cocaína.

Kokoreff et al. (2018) destacam igualmente que, em 1969, uma série de overdoses noticiadas pela imprensa provocou uma discussão de contornos dramáticos envolvendo o uso dessas substâncias. Por um lado, os artigos de jornal teriam contribuído para uma visão muito emocional sobre a relação entre jovens e drogas. Por outro, havia implicitamente um grande interesse do Estado em legiferar sobre a 
repressão às drogas tendo em vista o intuito de aumentar o controle e a manutenção da ordem social, face às contestações políticas que enfrentava. De fato, os casos de overdose eram pontuais, mas sua exposição serviu de justificativa às medidas legislativas tomadas, sob o argumento de proteção à juventude ameaçada.

Decorre dessa época que a pessoa usuária de psicoativos tenha sido categorizada pela psiquiatria como toxicômano e o seu consumo tenha passado a ser compreendido por meio de uma escalada da toxicomania. Esta se iniciaria pelo consumo de drogas consideradas como mais leves e terminaria pelo consumo de drogas mais pesadas. A fase da heroína seria, segundo essa teoria, a mais degradante. Nela, o usuário habitual era designado como junky e associado à ideia de que essa droga leva a um impasse mortal do qual não se pode sair (KOKOREFF et al., 2018).

Conquanto, não podemos deixar de ressaltar que a relação entre o estigmatizado (usuário de substâncias psicoativas) e o outro (aqueles que se consideram "normais") são socialmente complementares, isto é, fazem parte dos processos de interação social (GOFFMAN, 2008). Desse modo, entre toxicômanos e normais há uma necessária relação social. Adicionalmente, Machado Pais (2003, p. 205), em estudo sobre as culturas juvenis em Lisboa, enfatiza que: "o consumo de drogas toma significações diferentes segundo as especificidades culturais e as experiências simbólicas dos diferentes grupos que o consumo da droga acaba por reforçar".

A compreensão de Machado Pais (2003) é corroborada por Kokoreff et al. (2018) quando afirmado que os usos de drogas são tão diversos quanto são seus usuários. Entre esses últimos, existem aqueles que controlam o uso ou aqueles que alternam as substâncias e os períodos de consumo. Sendo assim, o uso de drogas pode ter um significado particular para cada pessoa e, além disso, há muitos usuários que gerenciam o próprio consumo conseguindo manter a atividade profissional, pausar o uso sazonalmente ou alterná-lo com outros tratamentos. 
A tese de Dos Santos (2016), que se propõe a uma espécie de estudo comparado, também apresenta parte de uma de genealogia acerca do consumo de substâncias psicoativas nas diferentes localidades por ela analisadas (França, Suíça e Quebec). A autora destaca a existência de uma "relativização da norma de abstinência" (DOS SANTOS, 2016, p. 133) ao longo dos anos 1980. Salienta haver esforços para se repensar a toxicomania. Conforme a obra citada, vários estudos procuravam mostrar que negar o consumo era ineficaz e se construiu então uma tendência a aceitar o consumo eventual. Além disso, um outro modo de admissão do consumo de drogas consistiu na estabilização por meio da metadona, no caso de uso dos opiáceos. Essa nova maneira de encarar o uso de drogas anunciava a futura flexibilização quanto ao modelo de reclusão dos usuários.

Desse modo, a redução dos danos foi sendo introduzida como parte da normalização do uso de drogas mesmo antes de sua adoção oficial pelo Estado. Nesse novo contexto, o usuário foi transformado em agente ativo da redução de danos. Isso muda duas importantes compreensões sociológicas, o seu papel social nos processos de interação social, bem como seu status, pois ele assume responsabilidade em relação à saúde e aos prejuízos que se pode causar a ela (GOFFMAN, 2004).

\section{CONSIDERAÇÕES FINAIS}

A partir do estudo que objetivou analisar a constituição discursiva interposta acerca das Salas de Consumo a Risco Reduzido no debate público francês, foi observado que a implantação destes estabelecimentos na França foi historicamente antecedida pela própria construção do uso de drogas enquanto um problema social e estigmatização dos usuários de psicoativos. A apreensão deste problema se deu, inicialmente, pelo meio político e médico de forma austera e proibitiva, com resultados nefastos em termos de marginalização e adoecimento daqueles usuários.

Uma vez que nossa questão inicial buscava compreender os aspectos sociais que conduziram a passagem do proibicionismo à adoção do modelo de moderação e

RC: 100364

Disponível em: https://www.nucleodoconhecimento.com.br/ciencias-sociais/drogasna-franca 
redução de danos, podemos concluir que tal transição decorreu da constituição de um campo de controvérsias o qual inseriu o tema no debate público francês. Face aos desafios sanitários lançados, a pauta da redução de danos no consumo de psicoativos se tornou do domínio da saúde pública, com novos atores configurando esse campo. Impulsionado por ações em esferas menores, o assunto atingiu grande amplitude e levou à negociação das condições de implantação, em 2016, daqueles estabelecimentos que visam amenizar a vulnerabilidade das pessoas que consomem substâncias injetáveis.

De acordo com os documentos analisados (artigos científicos e teses), observamos que o modelo proibicionista anteriormente vigente se associa a um ideal pautado na abstinência, enquanto o da redução de danos, que o substituiu, se vincula à lógica da moderação. Infere-se que há um consenso entre os/as autores/as acerca da compreensão de que uma Sala de Consumo é uma estrutura que, por estar inscrita em um modelo disciplinar de redução de danos, permite o consumo por meio da moderação, em oposição ao modelo de proibição.

Os autores Le Breton (2012a, 2012b), Dos Santos (2016), Kokoreff et al. (2018), Jaufret-Roustide e Cailbault (2018) se alinham à ideia de que, a partir do entendimento de que o uso regular de drogas e a busca pela vida não necessariamente se opõem, as Salas de Consumo parecem surgir como um meio de assegurar uma existência digna aos usuários, pois seu trabalho vai além da disponibilização de um local de cuidados higiênicos e protegido. Essa noção é importante pois possibilita a redefinição de papéis sociais e do status dos usuários de substâncias psicoativas. Estes espaços confeririam assim aos consumidores de drogas a recuperação do status de sujeito. O uso de drogas com risco controlado nesse local pode indicar que a pessoa procura o consumo lúcido, a gestão ritualizada que leva em consideração a limpeza, a quantidade, a frequência e a redução de danos. Por meio desse processo, a pessoa alcançaria o mundo do sensível através das drogas, mas pelo uso moderado, ela reivindicaria sua racionalidade, sua capacidade de tomar decisões que a sociedade considera razoáveis.

RC: 100364

Disponível em: https://www.nucleodoconhecimento.com.br/ciencias-sociais/drogasna-franca 
Contudo, como se viu pela escassa produção científica identificada até o momento da realização deste trabalho, mais estudos são necessários a fim de identificar se, de fato, as Salas de Consumo permitem trazer um sentimento de adequação aos que não se sentem condizentes com os padrões sociais de conduta, no caso, os usuários de substâncias psicoativas que as frequentam. Ademais, acreditamos ser importante pesquisar se a retomada do status de sujeito veiculada pelo uso de substâncias em Salas de Consumo permite que a autonomia e a adição às drogas coexistam, uma fazendo contrapeso à outra. Em síntese, em se tratando de uma estrutura relativamente recente e desconhecida por muitos países, o assunto merece ser melhor investigado, principalmente, privilegiando o ponto de vista de seus frequentadores.

Conclui-se que a superação das controvérsias acerca do debate pode contribuir para a (des)estigmatização de usuários de substâncias psicoativas, redefinindo seu papel social e status nos processos de interação em sociedade. Sendo assim, compartilhamos esta discussão com o público brasileiro acreditando poder contribuir para o debate sobre a adoção de medidas de redução de danos para as populações afetadas pelas drogas no país. Historicamente marginalizadas e distanciadas dos serviços de saúde, essas pessoas são o público-alvo das Salas de Consumo de Drogas a Riscos Reduzido, que se propõem a amenizar a sua vulnerabilidade.

\section{REFERÊNCIAS}

ARISTÓTELES. Éthique à Nicomaque. Paris: Flammarion, 1992.

BARDIN, Laurence. Análise de conteúdo. São Paulo: Edições 70, 2009.

BOLTANSKI, LUc, THÉVENOT, Laurent. De la justification. Les économies de la grandeur. Paris: Gallimard, 1991.

DOS SANTOS, Marie. Usages de traitements de substitution aux opiacés: étude comparative: France, Suisse et Québec. 2016. Tese (Doutorado) - Curso de ciências humanas e sociais, Universidade de Estrasburgo, Estrasburgo, 2016.

RC: 100364

Disponível em: https://www.nucleodoconhecimento.com.br/ciencias-sociais/drogasna-franca 
ESCOHOTADO, Antonio. Historia de las Drogas, vol. 3. Madri:Alianza, 1998.

FASSIN, Didier. Entre politiques du vivant et politiques de la vie: pour une anthropologie de la santé. Anthropologie et sociétés, v. 24, n. 1, p. 95-116, 2000.

FOUCAULT, Michel. Le sujet et le pouvoir. Dits et écrits. 1982. v. 4, p. 222-243.

FOUCAULT, Michel. Surveiller et punir. Naissance de la prison. Paris: Gallimard,1975.

GARRAU, Marie. Politiques de la vulnérabilité. Paris: CNRS éditions, 2018.

GOFFMAN, Erving. Estigma: notas sobre a manipulação da identidade deteriorada. 4⿳亠丷厂 ed. Lisboa: LTC, 2004.

JAUFFRET-ROUSTIDE, Marie; CAILBAULT, Isabelle. Drug consumption rooms: comparing times, spaces and actors in issues of social acceptability in French public debate. International Journal of Drug Policy, v. 56, p. 208-217, 2018.

JAUFFRET-ROUSTIDE, Marie. Les salles de consommation à moindre risque. Esprit, n. 11, p. 115-123, 2016.

JOAS, Hans. La créativité de l'agir. In : BAUDOUIN, Jean-Michel. Théories de l'action et éducation. Louvain-la-Neuve: éd. De Boeck Supérieur, 2001. p. 27-43.

KOKOREFF, Michel.; COPPEL, Anne.; et PERALDI, Michel. et al. La catastrophe invisible. Histoire sociale de l'héroïne. Paris: Amsterdam Editions, 2018.

LE BRETON, David. Le contrecorps de la toxicomanie. Sociographe, n. 3, p. 55-64, 2012a.

LE BRETON, David. Sociologie du risque. Paris: Presses universitaires de France, 2012b. 
MACHADO PAIS, José. Culturas Juvenis. $2^{\underline{a}}$ ed. Lisboa: Imprensa Nacional-Casa da Moeda, 2003.

MILDECA - Mission interministérielle de lutte contre les drogues et les conduites addictives, 2016. Les évaluations scientifiques de l'expérimentation des salles de consommations à moindre risque. Disponível em: https://www.drogues.gouv.fr/sites/drogues.gouv.fr/files/atoms/files/20161128_j_restit _scientif_evaluations_experimentations_scmr_def.pdf. Acesso em: 20 jan. 2019.

OEDT - Observatório europeu da droga e da toxicodependência, 2017. Salles de consommation de drogues: un aperçu de l'offre et des réalités. Disponível em: https://www.emcdda.europa.eu/topics/pods/drug-consumption-rooms_fr. Acesso em: 24 jun. 2019.

TROUESSIN, Mélanie. L'addiction comme pathologie de la volonté: repenser l'impuissance de la volonté à la lumière des sciences cognitives. 2017.Tese (Doutorado) - Curso de filosofia, Universidade de Lyon, Lyon, 2017.

VALENTIN, Claire Chaptal. Ouverture d'une salle de consommation à moindre risque (SCMR): attentes des usagers de drogues. 2018. Tese (Doutorado) Universidade de Estrasburgo, Estrasburgo, 2018.

\section{APÊNDICE - REFERÊNCIA NOTA DE RODAPÉ}

\section{Autoajuda para usuários de droga.}

5. Trata-se de um recorte de Dissertação de Mestrado em Ética e Sociedade, da Faculdade de Ciências Sociais da Universidade de Estrasburgo, França, realizada em 2019.

6. Instituto Nacional da Saúde e da Pesquisa Médica

7. Centro de pesquisa medicina, ciências, saúde, saúde mental, e sociedade.

RC: 100364

Disponível em: https://www.nucleodoconhecimento.com.br/ciencias-sociais/drogasna-franca 
8. Assim popularmente chamados os usuários que levavam a experimentação de drogas até as últimas consequências.

9. Termo em francês que se refere a periferias.

Enviado: Outubro, 2021.

Aprovado: Novembro, 2021.

RC: 100364

Disponível em: https://www.nucleodoconhecimento.com.br/ciencias-sociais/drogasna-franca 